\title{
UPAYA E-GOVERNMENT MELALUI BUDAYA INTRANET E-LEARNING PADA SEKOLAH DASAR DI KOTA MALANG (Studi pada Dinas Pendidikan Kota Malang)
}

\author{
Suljatmiko \\ STISOSPOL WASKITA DHARMA MALANG \\ Program Studi Ilmu Administrasi Publik \\ E-mail: suljatmiko0775@gmail.com
}

\begin{abstract}
Abstrak:
Pembentukan budaya tertib administrasi bagi pendidik dan peserta didik di sekolah tidak lepas dari rutinitas yang dilahirkan kebijakan sekolah. Penguasaan penggunaan media Teknologi Informasi dan Komunikasi (TIK) akan berdampak besar pada upaya penerapan e-Government di Indonesia, yang diimplentasikan sebagai program pemerintah dalam efektif pengefisienkan pelayanan publik. Budaya administrasi yang bersifat konvensional masih tertaman dalam tatakelola individu sampai tingkat instistusi. Seperti halnya rutinitas dalam melakukan pengukuran, pengadministrasian dan pelaporan masih menggukanan budaya konvensional. Budaya lain konvensional seperti akreditasi, pengendalian sekolah dalam tatakelola, dan dokumentasi tampak nyata. Rutinitas konvensional ini dapat berpengaruh terhadap lambatnya program-progam pemerintah khususnya pada upaya transformasi menuju e-Government. Penelitian dengan pendekatan kualitatif ini fokus pada permasalahan tentang budaya penerapan intranet e-Learning pada sekolah di Kota Malang, serta faktor yang menjadi pendukung dan penghambat dalam penerapan intranet e-Learning di sekolah. Analisis data yang digunakan adalah analisis model interaktif dan analisis medan kekuatan (Force Field Analysis). Hasil penelitian menunjukkan bahwa budaya menggunakan intranet e-Learning dapat dijadikan sebeagai pembiasaan menujuan upaya e-Govermnet. Optimalisasi e-Government dapat terwujud bilamana dasar berkegiatan pengadministrasian yang membudayakan intranet e-Learning secara rutin di sekolah. Dengan membudayanya intranet e-Learning di sekolah maka program pemerintah khususnya transformasi menuju e-Government dapat tercapai.
\end{abstract}

Kata Kunci: e-Government, intranet, e-Learning, administrasi, tatakelola, budaya, sekolah.

Abstract:

The formation of an orderly culture of administration for educators and students in schools cannot be separated from the routines that were born in school policy. Mastery of the use of Information and Communication Technology (ICT) media will have a major impact on efforts to carry out of e-Government in Indonesia, which is implemented as a government program in effectively streamlining public services. Conventional administrative culture is still secure in person management to the level of institutionalization. Like routine measurement, administration and reporting still use conventional culture. Other conventional cultures such as accreditation, school control in governance, and documentation are clear. This conventional routine can affect the slow pace of government programs, especially in the transformation efforts towards eGovernment. Research with this qualitative approach focuses on issues about the culture of e-Learning intranet implementation in schools in Malang, as well as factors that support and hinder the implementation of e-Learning intranet in schools. Analysis of the data used is interactive model analysis and force field analysis. The results showed that the culture of using the e-Learning intranet can be used as a habit towards eGovernment efforts. Optimization of e-Government can be realized if the basis of administrative activities that cultivate e-Learning intranet routinely at school. By cultivating the e-Learning intranet in schools, government programs especially the transformation towards e-Government can be achieved.

Keywords: e-Government, intranet, e-Learning, administration, governance, culture, school.

\section{PENDAHULUAN}

Era digitalisasi administrasi pada lembaga pemerintah maupun swasta pada saat ini masih belum menunjukkan situasi yang optimum, khususnya pada sekolah-sekolah dasar negeri dan swasta yang berada di Kota Malang. Hal ini diperlihatkan pada kegiatan tatakelola disekolah yang masih 
menggunakan model konvensional, seperti halnya kegiatan akreditasi sekolah, pengaministrasian buku induk sekolah. Begitu juga dengan cara melakukan pengukuran dan pengisian data lain yang berhubungan dengan tatakelola sekolah. Seperti halnya rangkaian dalam menerbitkan sebuah pelaporan kepada orang tua peserta didik yang masih menunjukkan model belum terdigitalisasi. Menurut [1] dalam pengembangan e-Government di Indonesia, "pada saat ini pemaknaan implementasi $e$ Government oleh pemerintah daerah maupun pusat masih banyak yang bersifat sendirisendiri, sehingga masih banyak kendala, hambatan dan tantangan yang dihadapi untuk meningkatkan pemanfaatan e-Government". Hal ini dapat menghambat upaya $e$ Government dalam sebuah pemerintah.

Intranet e-Learning adalah sebuah budaya dasar dalam membentuk rutinitas dalam upaya realisasi e-Government. Dengan upaya e-Government melalui budaya intranet e-Learning di sekolah merupakan panggilan untuk mengadopsi Teknologi Informasi dan Komunikasi (TIK) dalam mengelola fungsinya dalam dan dengan demikian berjalan digital / elektronik. Menurut [2] "Metode Pemeringkatan e-Government Indonesia Tata Kelola Teknologi Informasi" menekankan pada peralatan yang dimiliki sekolah.

Dengan rutinitas intranet e-Learning di sekolah dasar sehingga dapat membentuk budaya yang dapat dijadikan sebagai modal dasar dalam upaya menjadikan pemerintahan yang siap e-Government yang akan memenuhi kebutuhan dan kepentingan bangsa kita secara efisien. E-Government berjanji dapat membuat pemerintahan yang lebih efisien, responsive, sah dan transparan.

\section{KAJIAN TEORI}

\section{A. Intanet}

Adalah sebuah jaringan local yang dibuat layaknya seperti sebuah internet. Didalam intranet terdapat server dan client yang selalu berinterkasi dalam keluar masuknya paket data. Intranet dibatasi oleh kekuatan antena dan server, sehinga daya jangkauan sebatas Local Arena Network (LAN) yang dibangun.
Internet memang beda dengan intranet tetapi mempunyai fungsi yang sama .

Menurut [3] dalam membangun portal intranet menjelaskan bahwa intranet merupakan suatu bentuk pemanfaatan teknologi internet dalam sebuah organisasi atau perusahaan. Intranet dapat dioperasikan dalam Local Arena Network (LAN) atau Wide Area Network (WAN).

Dalam pengantar Jaringan Komputer dalam penjelasanya bahwa sebuah jaringan intarnet tidak memerlukan jaringan internet, biasanya tidak semua intranet disambungkan ke area public [4], administrator berperan mengatur lalulintas informasi.

Dalam penjelasan [5] Intranet adalah sistem yang menghubungkan semua komputer dalam suatu institusi. Ini adalah jaringan pribadi yang memanfaatkan protokol Internet untuk membagikan bagian data organisasi pada anggota.

Dengan demikian intranet adalah sebuah jaringan lokal yang berfungsi seperti jaringan internet, yang dapat berkomunikasi antara user dan administrator.

\section{B. e-Learning}

e-Learning sebagai media alat bantu dalam pendekatan yang menggunakan berbagai teknologi internet dan web yang memungkinkan, untuk membangkitkan dan memotivasi, juga untuk media mempromosi dan atau untuk mempresentasikan proses pembelajaran dan pengembangan kompetensi. Dengan sistem pembelajaran berbasis web dan kualifikasi arsitektur baru dapat dikirimkan ke mana-mana sehingga tepat pada waktu dan dengan standar kualitas yang seragam.

Menurut [6] dalam dampak e-Learning dalam pendidikan mengemukakan bahwa $e$ Learning merupakan kemasan cara belajar modern, yang menggunakan bantuan media elektronik. E-Learning memanfaatkan Teknologi Informasi dan Komunikasi (TIK). Pembelajaran korespondensi atau pembelajaran jarak jauh adalah situasi di mana e-Learning dapat dipergunakan untuk dapat mengefisiensikan administrator. $E$ Learning melibatkan berbagai jenis media yang menyediakan audio, video, teks dan 
gambar. E-Learning memanfaatkan intranet atau ekstranet atau internet, dan memperluas cakrawala pembelajaran tradisional.

Menurut [7] dalam penelitianya bahwa $e$ Learning dan e-Govenrment merupakan suatu pendekatan berbasis proses pelatihan dan belajar dalam lingkungan administrasi publik.

Dalam hal ini intranet e-Learning merupakan sebuah kegiatan belajar dan mengajar yang menggunakan bantuan alat elektronik dimana antara pendidik dan peserta didik tidak dibutuhkan tatap muka. Pengisian data induk dan pengerjaan quiz dapat dilakukan dengan cara semi online.

\section{E-Government}

Adalah bentuk pelayanan dalam meningkatkan semua cabang pemerintahan dan bukan hanya pada sektor administrasi public dalam arti sempit. E-Government bukan hanya menyangkut tentang infrastruktur atau strategi teknologi tetapi lebih baru dalam gaya organisasi administrasi publik dan operasi, namun e-Government adalah budaya dalam pelayanan sebuah pemerintahan. Adalah sebuah keberuntungan e-Government bilamana menggunakan e-Learning. Seperti yang dikemukakan [8] e-Government adalah dasar layanan termasuk dalam tindakan, seperti mengunduh dokumen atau mengisi formulir online, yang bisa dengan mudah dilakukan pengguna e-Government dengan pengetahuan dasar Teknik Informasi. Menurut [9] bahwa e-Government didefinisikan sebagai transformasi proses tatakelola pemerintah secara terus menerus dan eksponensial kepada masyarakat sehingga menghasilkan layanan berbentuk teknologi digital yang lebih maju. Senada dengan [10] peran $e$ Government sebagai cara pemerintah dalam memanfaatkan Teknologi Informasi dan Komunikasi yang paling inovatif, logis, yang menggunakan jaringan internet berbasis web aplikasi, dalam menyediakan bisnis dengan akses lebih mudah pada warga negara untuk mengakses informasi dan layanan pemerintah, dalam meningkatkan kualitas layanan dan memberikan peluang lebih besar dalam berpartisipasi dan proses demokrasi dalam institusi.
Dengan demikian e-Government adalah memotivasi kekadaan pemerintahan dalam mengefisiensikan pelayanan pada sektor publik sehingga dapat menekan biaya ekonomi yang rendah dan tepat sasaran.

\section{METODE}

Jenis penelitian yang dipakai penulis adalah penelitian dengan pendekatan kualitatif. Dengan fokus penelitian dalam penelitian upaya e-Government melalui budaya intranet e-Learning di sekolah dasar di Kota Malang (Studi pada Dinas Pendidikan Kota Malang) sebagai berikut: 1. Budaya penggunaan intranet e-Learning dalam sistem belajar dan mengajar di sekolah. 2. Faktor pendukung dan penghambat dalam upaya penerapan $e$ Government terkait dengan pengelolaan intranet e-Learning di sekolah. yaitu: a. Faktor pendukung: 1) Peraturan dan kebijakan sekolah yang tertuang di dalam visi dan misi sekolah; 2) Kertersedianya sarana dan prasarana; 3) Ketersediaan Sumber Daya Manusia (SDM); 4) Ketersediaan anggaran dana; b. Faktor penghambat: 1) Komitmen yang berubah-ubah dalam implementasi visi dan misi sekolah; 2) Tatakelola sarana dan prasarana; 3) Kualitas Sumber Daya Manusia (SDM). 4) Koordinasi tingkat operator. Analisis data yang digunakan dalam penelitian ini adalah dengan analisis model interaktif. Analisis dilakukan secara interaktif yang terdiri dari reduksi data, penyajian data, dan penarikan kesimpulan [11]. Selain menggunakan tahapan analisis data diatas, penelitian ini juga menggunakan Force Field Analysis atau analisis medan kekuatan [12]. Analisis ini digunakan untuk menganalisis berbagai faktor pendukung dan faktor penghambat dalam penerapan e-Government terkait dengan sistem intranet e-Learning di dunia pendidikan khususnya di sekolah dasar di Kota Malang. Metode Pengumpulan Data Menurut [13], bahwa teknik pengumpulan data merupakan suatu langkah yang paling strategis dalam suatu penelitian, karena tujuan utama penelitian adalah untuk mendapatkan data, dan bersumber pada data tersebut peneliti dapat melakukan analisis yang pada akhirnya peneliti akan menemukan substansi yang dipermasalahkan dalam 
rumusan masalah. Metode pengumpulan data yang digunakan adalah dengan metode Observasi, Wawancara dan Dokumentasi. Peneliti melakukan pengamatan baik secara langsung maupun tidak langsung terhadap objek yang diteliti. Wawancara dilakukan dengan tujuan untuk menggali dan memperoleh informasi dari objek yang diteliti. Peneliti melakukan wawancara dengan informan yang dianggap potensial untuk mengali informasi yang relevan dengan tujuan penelitian. Adapun informan dalam penelitian ini adalah sebagai berikut:

1) Kepala Seksi Sarana Prasarana Bidang Pembinaan Pendidikan Kota Malang; 2) Pengawas Sekolah Dasar Kota Malang; 3) Ketua Kelompok Kerja Kepala Sekolah (K3S); 4) Kepala SDN Lowokwaru 2 Kecamatan Lowokwaru; 5) Pendidik, proktor dan teknisi tingkat sekolah dasar. Disamping itu, pengumpulan dokumen baik dokumen resmi, referensi buku, jurnal, laporan penelitian dan karya ilmiah lainya digunakan dalam memperkaya data sebagai informasi dalam penelitian ini.

\section{HASIL DAN PEMBAHASAN \\ HASIL}

\section{Budaya penggunaan intranet e-Learning dalam sistem belajar dan mengajar di sekolah.}

Sekolah di kota Malang telah membangun visi dan misi yang menjadikan sekolah sebagai tempat tumbuh kembang peserta didik yang unggul dalam IMTAQ, IPTEK, berbudi pekerti luhur dalam Kurikulum Tingkat Satuan Pendidikan (KTSP) [14]. Demikian juga dengan misi sekolah yang mengembangkan pembelajaran keterampilan dan teknologi ramah lingkungan yang sesuai bakat dan minat peserta didik. Peralihan ekstrakurikuler TIK menjadi muatan sekolah yang dapat memperkuat budaya penggunaan median TIK. Modul bahan ajar yang sebagai sarana budaya Intranet e-Learning masih terbatas pada pengukuran bidang studi TIK. Modul-modul lain masih menggunakan penyampaian konvensional. Adapun pengukuran yang menggunakan intranet e-Learning masih sedikit, hanya sebagian sekolah saja yang menggunakan intranet e-Learning. Adapun sekolah yang sudah menerapkan pembelajaran melalui int/ranet e-Learning sebagai berikut:

Tabel 1. Penyampaian modul belajar.

\begin{tabular}{|l|c|c|}
\hline $\begin{array}{l}\text { Tahun } \\
\text { Pelajaran }\end{array}$ & $\begin{array}{c}\text { Cara } \\
\text { Konvensional }\end{array}$ & $\begin{array}{c}\text { Melalui } \\
\text { Intranet } e- \\
\text { Learning }\end{array}$ \\
\hline $2017 / 2018$ & & \\
\hline $2018 / 2019$ & & \\
\hline $2019 / 2020$ & & \\
\hline
\end{tabular}

Sumber : Data peneliti diolah, 2019

Himbauan dari Kepala Dinas Pendidikan Kota Malang tentang Ujian Sekolah Berbasis Komputer (USBK) yang dilakukan serentak di lima kecamatan di kota Malang sebagai tonggak dimulainya transformasi ujian berbasis kertas menuju semi online (intranet). Pedoman Ujian Berbasis Komputer dari Badan Nasional Standar Pendidikan (BNSP) Tahun 2019 yang mengatur tatacara melakukan Ujian Sekolah Berbasis Komputer [15]. Ini menujukkan bahwa budaya dalam menggunakan intranet e-Learning sudah dilakukan di tiap sekolah dasar di kota Malang. Namun hanya sebatas pengukuran pada beberapa mata ujian saja. Sehingga budaya dalam menggunakan intranet $e$ Learning sebatas ujian akhir sekolah pada kelas 6 sekolah dasar.

Dalam wawancara dengan Kepala Seksi Sarana Prasarana Bidang Pembinaan, "Ujian Sekolah Berbasis Komputer (USBK) pada jenjang sekolah dasar menggunakan jaringan intranet atau semi online". Selain itu wawancara dengan Pengawas Kepala Sekolah menambahkan bahwa "Ujian Sekolah Berbasis Komputer (USBK) di kota Malang tidak menggunakan internet tetapi menggunakan jaringan intranet atau jaringan sekolah, nanti pada saat pengiriman hasil ujian atau sinkronisasi dilakukan dengan menggunakan internet".

Hal lain pada saat wawancara dengan Ketua Kelompok Kerja Kepala Sekolah (K3S) yang juga selaku Kepala Sekolah SDN Lowokwaru 3 kota Malang menjelaskan bahwa "Ujian Sekolah Berbasis Komputer (USBK) di kota Malang adalah sebagai contoh daerah lain 
yang belum menerapkan intranet $e$-Learning atau semi online.

Secara mendalam dikemukanan oleh Kepala SDN Lowokwaru 2 Kota Malang yang megatakan bahwa "sekolah kami mengunakan intranet e-Learning sudah dikakukan sejak tahun 2013, sebelum ada himbauan tentang USBK, namun hanya sebatas pembelajaran Teknologi Informasi dan Komunikasi (TIK), namun pada saat ini sekolah kami mulai dari kelas 3 sampai kelas 6 sudah membudayakan pengukuran dengan menggunakan Hand Phone atau Tab.

Sejalan dengan pendidik kelas 6 sekaligus proktor ujian SDN Dinoyo 4 Kota Malang mengatakan bahwa Ujian Sekolah Berbasis Komputer (USBK) dapat mengurangi beban guru kelas saat mengoreksi, hal ini dapat mengefisiensikan waktu dan mempermudah tugas-tugas guru dalam mengadministrasikan hasil pembelajaran.

Data jumlah sekolah yang sudah menerapkan intranet e-Learning di kota Malang sebagai berikut:

Tabel 2. Jumlah Sekolah yang menggunakan intranet e-Learning pada saat pengukuran

\begin{tabular}{|l|c|c|}
\hline $\begin{array}{c}\text { Status } \\
\text { Sekolah Dasar }\end{array}$ & $\begin{array}{c}\text { Tahun } \\
2017 / 2018\end{array}$ & $\begin{array}{c}\text { Tahun } \\
2018 / 2019\end{array}$ \\
\hline Negeri & 28 & 198 \\
\hline Swasta & 54 & 80 \\
\hline Jumlah & 82 & 278 \\
\hline
\end{tabular}

Sumber: Data peneliti diolah, 2019

Disamping itu penggunaan intranet $e$-Learning dalam kegiatan administrasi bagi para tenaga kependidikan sudah cakap dalam mengisi form melalui aplikasi yang online atau semi online, seperti Dapodik, Simbada, Simas, Pemetaan Mutu Pendidikan (PMP) daftar nominasi ujian dan daftar nilai sekolah. Pengelolaan web sekolah juga mendominasi kecakapan para tenaga kependidikan di sekolah.

Rutinitas pengisian hasil laporan pendidik kepada orang tua atau wali melalui paket aplikasi terpusat sekolah atau melalui media intranet e-Learning. Administrasi bentuk pengisian aplikasi laporan yang dibuat melalui intranet e-Learning seperti pada Gambar 1.
Gambar 1. Gambar halaman utama aplikasi adminsitrasi berbasis intranet-elearning ynag diakes melalui http://localhost/diriku

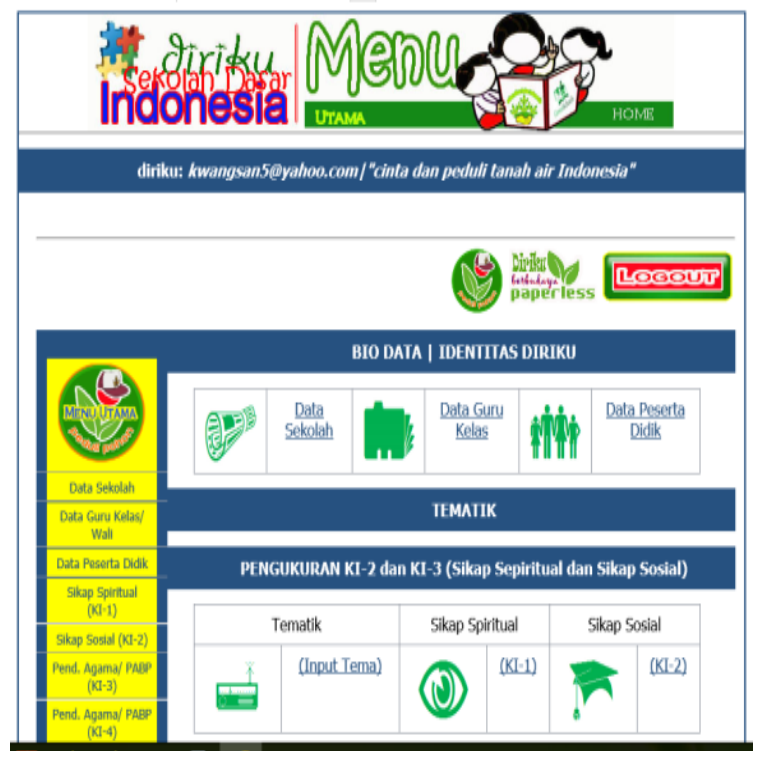

Sumber: Data peneliti diolah, 2019

Budaya lain dalam intranet e-Learning, terlihat pada saat sekolah menyampaikan sosialisasi terhadap orang tua peserta didik dengan memasukkan materi sosialisasi di dalam hand phone para hadirin dan komputer yang digunakan saat rapat di Laboratorium TIK.

2. Faktor pendukung dan penghambat dalam upaya penerapan e-Government terkait dengan pengelolaan intranet $e$ Learning di sekolah.

Menurut [16] dalam penelitianya menjelaskan bahwa dalam pelaksanaan di lapangan $e$ Goverment akan mengalami hambatan dan tantangan. Upaya e-Government melalui budaya intranet e-Learning di sekolah dasar di Kota Malang dianalisis dengan menggunakan Force Field Analysis (FFA). Force field analysis (FFA) ini digunakan untuk mengetahui kekuatan dari faktor pendukung dan penghambat dalam budaya intranet $e$ Learning di dunia pendidikan dasar di Kota Malang, dengan sistem intranet e-Learning dengan pemanfaatan teknologi informasi dan komunikasi.

Dalam melakukan analisis dengan menggunakan Force Field Analysis (FFA) 
peneliti menggunakan langkah-langkah sebagai berikut:

1. Menetapkan tujuan atau hasil.

Tujuan atau hasil yang dicapai yaitu sejauhmana budaya komponen sekolah dalam menggunakan intranet e-Learning pada sekolah. Dengan demikian dapat mengetahui rutinitas kegiatan dalam pembiasaan usaha pengadministrasian pendidikan, pelayanan dan tatakelola sekolah yang efisien dan canggih.

2. Mengidentifikasi kekuatan pendukung dan penghambat.

Dari hasil penelitian dilapangan maka dapat diidentifikasi faktor pendukung dan penghambat dalam upaya e-Government melalui budaya intranet e-Learning di sekolah dasar di Kota Malang, sebagai berikut:

1) Adanya peraturan dan kebijakan yang tertuang visi dan misi sekolah;

2) Ketersediaan sarana dan prasarana;

3) Ketersediaan sumber daya manusia;

4) Ketersediaan anggaran dana;

Adapun faktor penghambatnya adalah:

1) Komitmen yang berubah-ubah dalam implementasi visi dan misi sekolah;

2) Tatakelola sarana dan prasarana;

3) Kualitas sumber daya manusia;

4) Koordinasi tingkat operator dan pejabat pembuat komitmen.

3. Megukur potensi tingkat kekuatan dengan menentukan skor masing-masing kekuatan, dari skor 1 (lemah) sampai 5 ( sangat kuat). Penilaian potensi kekuatan dilakukan dengan menilai kekuatan pendukung dan kekuatan penghambat. Force Field Analysis (FFA) dilakukan dengan menggunakan metode pendekatan kualitatif. Peneliti melakukan penetapan skor dengan melihat data yang dilakukan saat penelitian tentang Upaya $e$ Government melalui budaya intranet $e$ Learning di sekolah dasar di Kota Malang. Adapun penentuan skor dapat dilihat dalam tabel berikut ini:

Tabel 3. Tabel Skor factor pedukung dan penghambat

\begin{tabular}{|c|c|c|c|}
\hline $\begin{array}{c}\text { Faktor } \\
\text { Pendukung }\end{array}$ & Skor & $\begin{array}{c}\text { Faktor } \\
\text { Penghambat }\end{array}$ & Skor \\
\hline
\end{tabular}

\begin{tabular}{|c|c|c|c|}
\hline $\begin{array}{l}\text { Adanya } \\
\text { peraturan } \\
\text { dan } \\
\text { kebijakan } \\
\text { yang } \\
\text { tertuang visi } \\
\text { dan misi } \\
\text { sekolah }\end{array}$ & 5 & $\begin{array}{l}\text { Komitmen } \\
\text { yang } \\
\text { berubah- } \\
\text { ubah dalam } \\
\text { implementasi } \\
\text { visi dan misi } \\
\text { sekolah }\end{array}$ & 4 \\
\hline $\begin{array}{l}\text { Ketersediaan } \\
\text { sarana dan } \\
\text { prasarana }\end{array}$ & 4 & $\begin{array}{l}\text { Tatakelola } \\
\text { sarana dan } \\
\text { prasarana }\end{array}$ & 4 \\
\hline $\begin{array}{l}\text { Ketersediaan } \\
\text { sumber daya } \\
\text { manusia }\end{array}$ & 4 & $\begin{array}{l}\text { Kualitas } \\
\text { sumber daya } \\
\text { manusia. }\end{array}$ & 3 \\
\hline $\begin{array}{l}\text { Ketersediaan } \\
\text { anggaran } \\
\text { dana }\end{array}$ & 4 & $\begin{array}{l}\text { Koordinasi } \\
\text { tingkat } \\
\text { operator }\end{array}$ & 3 \\
\hline Jumlah & 17 & Jumlah & 14 \\
\hline
\end{tabular}

Sumber: Data peneliti diolah, 2019

Berdasarkan data diatas, identifikasikan faktor pendukung dan faktor penghambat dalam upaya e-Government melalui budaya intranet elearning di sekolah dasar Kota Malang sebagai berikut:

1) Peraturan Pemerintah RI Nomor 19 Tahun 2005 tentang Standar Nasional Pendidikan. Pasal 1 ayat (15); Kurikulum Tingkat Satuan Pendidikan (KTSP) adalah kurikulum operasional yang disusun oleh dan dilaksanakan di masing-masing satuan pendidikan. Dimana sekolah menetapkan penanaman akhlak, ilmu pengetahuan dan teknologi dalam visi dan misi sekolah. Selain Dalam Prosedur Operasional Penyeleanggaran Ujian Berstandar Nasional Tahun 2018/ 2019 tentang Moda Ujian Berbasis Komputer (UBK) dapat dijadikan acuan dalam pelaksanaan budaya pengukuran melalui intranet $e$ Learning di kota Malang. Dengan demikian faktor adanya aturan dan kebijakan ini diberi bobot 5 (sangat kuat) sebagai faktor pendukung upaya e-Government melalui budaya intranet e-Learning di sekolah dasar di Kota Malang.

2) Ketersediaan sarana dan prasarana; Ketersediaan sarana dan prasarana 
pendukung merupakan faktor pendukung keberhasilan budaya intranet e-Learning. Tersedianya infrastruktur seperti server, jaringan intranet, jaringan internet, bandwidth, personal komputer, laptop, ruang administrasi, laoratorium komputer, laboratorium ruang ujian berbasis komputer. Hal lain yang mempengaruhi keberhasilan budaya intranet e-Learning adalah aplikasi web site semi online seperti sudah tersedia mulai yang dari aplikasi open source (moodle) sampai aplikasi dari Dinas Pendidikan Kota Malang. Faktor ini diberi bobot 4 (kuat) karena sarana prasarana mempunyai peranan yang penting dalam keberhasilan dari pelaksanan budaya intranet e-leaning pada sekolah dasar di Kota Malang.

3) Ketersediaan Sumber Daya Manusia (SDM); Sumber Daya Manusia (SDM) yang ada tentunya sangat menunjang pada program budaya intranet e-Learning. Pedidik di lingkungan sekolah disamping sudah tersertifikasi sudah juga sudah dibekali kursus dan pelatihan bidang TIK. Bahkan guru kelas juga ada mengampu pelajaran TIK. Khusus yang menangani Ujian Berbasis Komputer, ada teknisi komputer jaringan dan proktor. Peserta didik sendiri sudah menerima pelajaran keterampilan komputer pada bidang studi TIK. Ini dibuktikan adanya Lembar Kegiatan Siswa bidang TIK dari Dinas Pendidikan Kota Malang. Sedangkan khusus operator yang ditunjuk sebagai penanggunag jawan Ujian Sekolah Berbasis Komputer (USBK) semi online (intranet) dapat dilihat pada Tabel 4. dibawah ini:

Tabel 4. Jumlah operator intranet e-Learning

\begin{tabular}{|l|c|}
\hline \multicolumn{1}{|c|}{ Status sekolah } & Jumlah \\
\hline Negeri & 210 orang \\
\hline Swasta & 82 orang \\
\hline Total & 292 orang \\
\hline
\end{tabular}

Sumber: Data peneliti diolah, 2019

4) Faktor pendorong dimana ketersediaan Sumber Daya Manusia (SDM) diberi bobot 4 (kuat), karena secara kuantitas dirasa memenuhi dalam membudayakan upaya $e$ -
Government melalui upaya intranet $e$ Learning.

5) Ketersediaan Anggaran Dana; Sumber dana operasional sekolah berasal dari dana BOSNAS dan BOSDA. Anggaran yang diperuntukkan dalam intranet e-Learning sudah tercover dalam (Rencana Anggran dan Belanjan Sekolah (RABS) Sekolah masing-masing. Besaran masing-masing anggran tergantung pada jumlah siswa di masing-masing sekolah. Ini menunjukkan bahwa ada alokasi dana tersendiri yang digunakan dalam peningkatkan sarana prasarana bidang TIK dan peningkatan kompetensi pendidik dan tenaga kependidikan. Dari data diatas peneliti memberi bobot 4 (kuat) pada faktor pendukung bidang pendanaan.

Sedangkan faktor penghambat dalam upaya e-Government melalui intranet $e$-Learning di sekolah di Kota Malang adalah:

1) Komitmen yang berubah-ubah dalam implementasi visi dan misi sekolah pada Kurikulum Tingkat Satuan Pendidikan (KTSP) di masing-masing sekolah. Rotasi pimpinan sekolah adalah salah satu faktor yang menghambat kebijakan dan aturan. Dimana pimpinan baru akan menambah dan meprioritaskan program tertentu sekolah yang dianggap sebagai lebih penting seperti, pengelolaan lingkungan sekolah, penambahan dan perawatan gedung, mebelair, alat elektronik, pengadaan buku dan literasi lain. Dari data diatas bahwa pimpinan sekolah tidak hanya mengutamakan salah satu program saja namun memprioritaskan kebutuhan sesuai keadaan sekolah. Ini menunjukkan bahwa faktor penghambat juga kuat, maka peneliti memberi sekor kuat (4) terhadap faktor ini.

2) Tatakelola sarana dan prasarana; Tata kelola sarana dan prasara teruma di bidang Teknologi Informasi dan Komunikasi (TIK) sangat berperan pada faktor penghambat ini. Hal Ini dibuktikan bahwa banyak sekolah yang sudah mempunyai peralatan yang cukup, namu tidak digunakan untuk program-program lain. Pranata bantuan dari Dinas Pendidikan sebatas digunakan untuk waktu ujian akhir kelas 6 saja, 
namun kelas dibawahya tidak memanfaatkannya. Ada juga pemanfaatan hanya digunakan untuk mengetik saja. Hal ini menunjukkan bahwa pranata yang sudah ada kurang dimanfaatkan secara optimal. Oleh Karena itu pada faktor ini peneliti memberi skor 4 (kuat).

3) Ketersediaan kualitas Sumber Daya Manusia (SDM); Ketersediaan kualitas Sumber Daya Manusia (SDM) memegang peranan penting dalam faktor ini. Dari pengamatan peneliti sudah memenuhi, namun belum optimal. Beberapa tenaga pendidik yang sudah sudah tua banyak yang belum mengetahui tentang media intranet e-Learning, dalam proses belajar masih menggunakan cara konvensional. Berbeda dengan tenaga pendidik kelas 1 sampai kelas 5 yang masih muda. Mengetahui intranet e-Learning, namun belum pernah menerapkan dalam pembelajaran di kelas. Hal ini disebabkan karena mempersiapkan pranta-pranatanya yang dianggap kurang menguasai. Oleh karena itu peneliti memberi skor 3 (cukup kuat) dalam faktor penghambat pada upaya e-Government melalui budaya intranet e-Learning di sekolah.

4) Koordinasi tingkat operator; Dari hasil pengamatan penelitian, peneliti mendapatkan hasil bahwa kurangnya komitmen dalam menjalankan program intranet e-Learning di sekolah. Hal ini ditunjukkan bawah, operator ditingkat sekolah hanya akan merepon perintah untuk menggunakan program dari Dinas Pendidikan. Bagi operator yang sudah berpengalaman dapat men-create kebutuhan sekolah itu sendiri. Seperti pembuatan aplikasi sendiri yang berbasis open source. Koordinasi tentang intranet $e$ Learning masih individu sekolah masingmasing. Pada penskoran faktor ini peneliti memberi skor 3 (cukup kuat) dalam berbudaya intranet e-Learning di sekolah.

Design alalisis kekuatan upaya $e$ Government melalui upaya intraner $e$ Leraning di sekolah dalam faktor pedukung dan penghambat tampak seperti Gambar 2.

Gambar 2. Force Field Analysis (FFA) Upaya e-Government melalui budaya intranet e-Learning di sekolah

Dari data diatas maka dapat diketahui bahwa dalam upaya e-Government melalui budaya intranet e-Learning di sekolah di Kota Malang. Faktor pendukung lebih kuat daripada faktor penghambat.

\section{PEMBAHASAN}

Menurut [17] dalam penelitianya menjelaskan bahwa e-Learning merupakan strategi penerapan e-Government dalam pelayanan publik dan pengembangannya.

Dari hasil diatas maka peneliti menyimpulkan bahwa:

Budaya dalam menggunakan intranet $e$ Learning dalam upaya penerapan $E$ Government pada sekolah di Kota Malang mengalami peningkatan semenjak di selenggarakan Ujian Sekolah Berbasis Komputer (USBK) serentak di 5 Kecamatan di Kota Malang. USBK dielenggaran dengan dengan moda semi online (intranet). Ini dibuktikan dari peningkatan jumlah operator.

Sedangkan dari faktor pendukung dan penghambat disimpulkan:

1) Adanya kebijakan dan implementasi yang

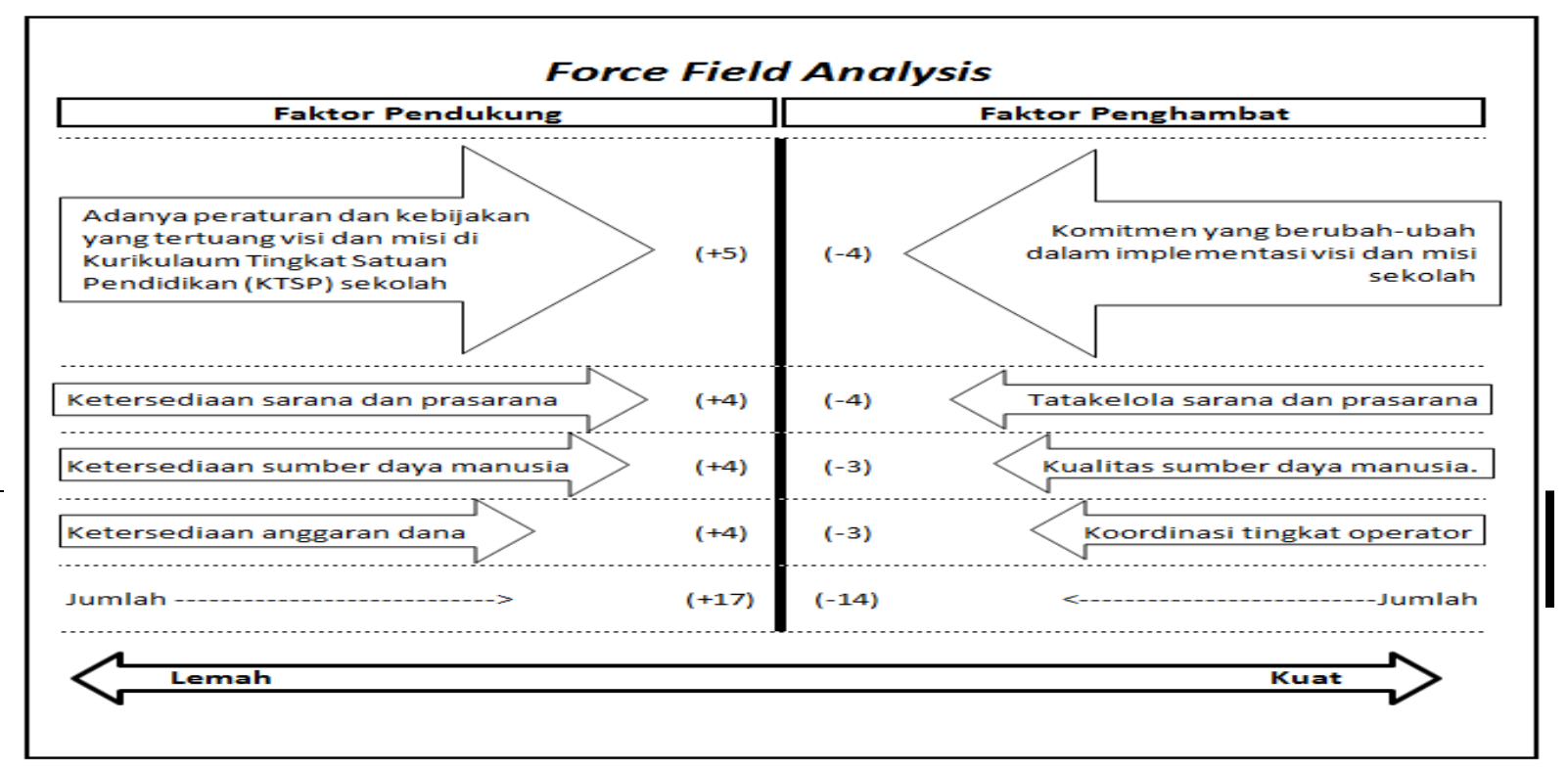


berubah, ini disebabkan karena pimpinan sekolah lebih memprioritaskan kebutuhan opersional lain yang mendesak. Dengan demikian untuk kebutuhan bidang teknologi dan membangun SDM dapat menerbitkan rumusan atau strategi kebijakan yang dapat mengifisiensikan kegiatan tatakelola pengadministrasian tanpa harus mengurangi kebutuhan utama dalam sekolah.

2) Pranata bidang TIK disetiap sekolah dasar negeri dan swata sudah memenuhi standar. Terutama sekolah negeri yang sudah mendapat bantuan komputer dari Dinas Pendidikan Kota Malang. Optimalisasi pranata Teknologi Informasi dan Komunikasi (TIK) yang ada di sekolah masih kurang, sehingga pengelolan sarana dan prasarana bidang TIK belum memenuhi upaya intranet e-Learning.

3) Pemetaan SDM dan meningkatkan kualitas SDM yang ada dengan memberi motivasi dan pelatihan (skill) terhadap pendidik pada media intranet $e$-Learning di sekolah. Belum adanya jalinan kerjasama dengan SMK jurusan Teknik Komputer dan Jaringan atau perguruan tinggi yang sudah kompeten bidang e-Learning.

4) Terdapat anggaran pengadaan dan perawatan bidang TIK, tetapi masih belum rutin, karena sekolah masih menganggarkan kebutuhan skala prioritas. Sedangkan dalam penganggaran peningkatan mutu SDM bidang TIK sebatas insidental. Penganggaran program intranet e-Learning belum berkelanjutan. Anggaran dalam peningkatan mutu dan pengembangan diri SDM juga masih berskala prioritas menyesuaikan dengan kegiatan yang diselenggarakan oleh Dinas Pendidikan atau kegiatan di tingkat kecamatan.

Dari pengukuran kekuatan melalui Force Field Analisys (FFA) faktor pendukung lebih kuat dibanding faktor penghambat dalam upaya $e$ Government melalui upaya intranet $e$ Learning di sekolah

\section{KESIMPULAN}

Penelitian tentang upaya e-Government melalui budaya intranet e-Learning di skolah dasar di Kota Malang (Studi pada Dinas Pendidikan di Kota Malang) menyimpulkan bahwa:

1. Budaya penggunaan intranet e-Learning dalam sistem belajar dan mengajar di sekolah.

Upaya e-Government melalui budaya intranet e-Learning dapat diterapkan pada semua sekolah di Kota Malang. Pengembangan IMTAQ dan IMTEK yang tertuang dalam Kurikulum Tingkat Satuan Pendidikan (KTSP) dapat menjadi dasar kebijakan dalam impementasi intranet $e$ Learning di sekolah. Budaya dan pengetahuan dasar dalam menerapkan $e$ Government dapat dimulai dari hal yang kecil yaitu dengan penerapan intramet $e$ Learning di tingkat pendidikan dasar. Dengan pembiasaan menggunakan intranet e-Learning dalam pembelajaran dan pengadministrasian maka kan menjadi budaya digitalisasi dan efisiensi dalam tata kelola administrasi dan pelayanan. Rutinitas penggunaan intranet e-Learning dapat membudaya dan melekat pada seluruh warga, sehingga pada saat dihadapkan pelayanan publik moda $e$ Governmet maka program-program pemerintah dapat berjalan sesuai dengan harapan. Kota Malang dapat menjadi kota rujukan yang dalam upaya penerapan $e$ Government.

2. Faktor pendukung dan penghambat dalam upaya penerapan e-Government terkait dengan pengelolaan intranet $e$ Learning di sekolah (Force Field Analysis)

A. Faktor Pendukung

1) Kebijakan pengembangan ilmu pengetahuan dan teknologi bidang TIK teruang dalam Kurikulum Tingka Satuan Pendidikan (KTSP) sekolah.

2) Pemerintah Kota Malang telah memberikan bantuan sarana dan prasarana berupa sejumlah Unit perangkat komputer dan jaringan sebagai bentuk dukungan dalam penerapan budaya e-Government melalui intranet e-Learning di sekolah. 
3) Sumber Daya Manusia (SDM) yang meliputi teknisi, proktor dan guru TIK sudah dimiliki oleh setiap sekolah.

4) Dukungan pendanaan dari BOSNAS dan BOSDA.

B. Faktor Penghambat

1) Komitmen yang berubah dalam pengembangan mutu sekolah.

2) Tatakelola sarana dan prasarana perangkat komputer dan jaringan.

3) Kurangnya kerjasama dengan pihak lain berkompeten bidang intranet e-Learning.

4) Pendanaan yang tidak rutin dan masih insidental.

Adapun saran-saran yang dapat penulis sampaikan adalah sebagai berikut:

1. Guna memperlancar program eGovernment, pemerintah melalui Dinas Pendidikan Kota Malang dapat menerbitkan aturan atau kebijakan terkait pembiasaan menggunakan intranet e-Learning di sekolah, sehingga seluruh sekolah menerapkan.

2. Bantuan sarana dan prasarana bidang TIK tetap berkelanjutan kepada sekolah negeri dan swasta.

3. Pergantian pimpinan sekolah yang tetap mengutamakan program efisiensi dan pelayanan administrasi sekolah.

4. Menunjuk sekolah kejuruan bidang komputer jaringan dan atau kerjasama dengan perguruan tinggi dalam pengembangan intranet $e$ Learning dan tatakelola sarana dan prasarana bidang TIK.

5. Optimalisasi kegiatan Kelompok Kerja Guru bidang intranet $e$-Learning.

6. Membentuk kerjasama dengan proktor dalam pengetahuan teknisi, perawatan dan pelayanan.

7. Rutinitas anggaran dalam pengembangan intranet e-Learning di sekolah.

\section{UCAPAN TERIMA KASIH}

Dengan selesainya penelitian ini, penulis mengucapkan terima kasih kepada semua pihak yang telah membantu dan mendukung baik secara substansi maupun finansial sehingga penelitian dengan judul Upaya $e$ Government Melalui Budaya Intranet $e$ Learning di Sekolah Dasar Kota Malang (Studi pada Dinas Pendidikan Kota Malang) dapat terselesaikan.

\section{DAFTAR PUSTAKA}

[1]. Simangunsong, Jumadi. "Pengembangan E-Government di Indonesia." Magister Teknologi Informasi, Universitas Indonesia, Jakarta (2010).

[2]. Fitriansyah, Ahmad, Hary Budiarto, and Joko Santoso. "Metode Pemeringkatan eGovernment Indonesia (PeGI) Untuk Audit Tata Kelola Teknologi Informasi." SESINDO 20132013 (2013).

[3]. Jhonsen. 2004. "Membangun Portal Intranet dengan Aplikasi Open Source Moregroupware" (2004). PT Elekmedia Komputindo,Jakarta.

[4]. Syarizal, Melwin, 2005," Pengantar Jaringan Komputer". (2005), Yogyakarta, Andi Offset

[5]. Azeta, Ambrose A., et al. "AN INTRANET PORTAL FOR A LEARNING INSTITUTION." (2015): 1227-1233.

[6]. Agarwal, Himanshu, and G. N. Pandey. "Impact of E-Learning in education." International Journal of Science and Research (IJSR) 2.12 (2013): 146-147.

[7]. Palkovits, Silke, J. Lorente, and Dimitris Karagiannis. "E-Learning and eGovernment: An approach for processbased training and learning in the public administration." Workshop on EGovernment: Legal, technical and pedagogical aspects. University of Saragoza:[sn]. 2002.

[8]. VELJKOVIĆ, NATAŠA, and LEONID STOIMENOV."E-LEARNING OPPORTUNITIES FOR E-GOVERNMENT." 
[9]. Kolachalam, Shivakumar. "An Overview of E-Government." Economia Aziendale Online 1 (2012): 1-12.

[10].Fang, Zhiyuan. "E-Government in digital era: concept, practice, and development." International journal of the Computer, the Internet and management 10.2 (2002): 1-22.

[11].Miles, Matthew B dan Huberman, Maichael A. (2014) "Qualitative Data Analysis". United States of America. Sage Publications.

[12].Force Field Analysis Model. www.changemanagementcoach.com/forcefieldanalysis.htmldiakses pada 10 Maret 2015 pkl. 14:12 wib

[13].Kaelan. 2013 "Metode Penelitian Kualitatif Interdisipliner bidang Sosial Budaya Filsafat Seni Agama dan Humaniora". Yogjakarta, Paradigma.

[14]. Peraturan Pemerintah RI Nomor 19 Tahun 2005 tentang Standar Nasional Pendidikan. Pasal 1 ayat (15); tentang Kurikulum Tingkat Satuan Pendidikan (KTSP)

[15].Peraturan Badan Standar Nasional Pendidikan Nomor: 0048/BSNP/XI/2018 Tentang Prosedur Operasional Standar Penyelenggaraan Ujian Sekolah Berstandar Nasional Tahun Pelajaran 2018/2019

[16].Sosiawan, Edwi Arief. "Tantangan dan Hambatan dalam implementasi EGovernment di Indonesia." Seminar Nasional Informatika (SEMNASIF). Vol. 1. No. 5. 2015.

[17]. Azeta, A. A., et al. "Voice-based eLearning Approach for eGovernment." Handbook of Research on E-Services in the Public Sector: E-
Government Strategies and Advancements. IGI Global, 2011. 25-33. 